\title{
Clinical efficacy of octreotide acetate combined with thrombin in the treatment of liver cirrhosis complicated with gastrointestinal hemorrhage
}

\author{
XIAOYAN WANG, YANYAN LIU, JINGJING ZHAO and JINMEI ZHANG \\ Department of Hepatological Surgery, Weifang People's Hospital, Weifang, Shandong 261041, P.R. China
}

Received October 12, 2018; Accepted February 11, 2019

DOI: $10.3892 /$ etm.2019.7345

\begin{abstract}
Clinical efficacy of octreotide acetate combined with thrombin in the treatment of liver cirrhosis complicated with gastrointestinal hemorrhage was investigated. A retrospective analysis of 157 patients with liver cirrhosis and gastrointestinal hemorrhage admitted to Weifang People's Hospital from March 2012 to September 2014 was performed. Among them, 74 patients treated with octreotide acetate were enrolled into the octreotide group, and 83 patients treated with octreotide acetate combined with thrombin were enrolled into the combination group. Comparison between the two groups was made in terms of the average hemostasis time, the hospitalization time, the amount of blood transfusion during hospitalization, the efficacy of hemostasis and visual analog scale (VAS) scores. The mean hemostasis time of the octreotide group was higher than that of the combination group, with a statistically significant difference between the two groups $(\mathrm{P}<0.05)$; the hospitalization time of the octreotide group was significantly longer than that of the combination group $(\mathrm{P}<0.05)$; the blood transfusion volume of patients in the octreotide group was significantly higher than that of the combination group $(\mathrm{P}<0.05)$; the overall effective rate of the combination group after treatment was higher than the overall effective rate of the octreotide group $(89.19 \%)(\mathrm{P}<0.05)$. The VAS scores of the combination group at 24 and $72 \mathrm{~h}$ after treatment were lower than those of the octreotide group $(\mathrm{P}<0.05)$; the VAS scores of both the octreotide and the combination group at 24 and $72 \mathrm{~h}$ after treatment were significantly lower than those before treatment $(\mathrm{P}<0.05)$. In conclusion, the combination of octreotide acetate and thrombin is worthy of clinical promotion as it could reduce the average hemostasis time, the bleeding volume, and the hospitalization time of
\end{abstract}

Correspondence to: Dr Jinmei Zhang, Department of Hepatological Surgery, Weifang People's Hospital, 151 Guangwen Road, Weifang, Shandong 261041, P.R. China

E-mail: jh98us@163.com

Key words: octreotide acetate, thrombin, liver cirrhosis, gastrointestinal hemorrhage, clinical efficacy patients with liver cirrhosis combined with gastrointestinal hemorrhage, with better efficacy than the use of octreotide acetate alone.

\section{Introduction}

Liver cirrhosis, the histological development of regenerative nodules surrounded by fibrous bands after chronic liver injury, can lead to portal hypertension and liver cancer, with high incidence in developed countries (1). Liver cirrhosis in the long-term can cause increased portal pressure, and cause the rupture of blood vessels in the upper digestive tract, especially esophageal gastric varices, resulting in acute bleeding, which is fierce and has fast disease progression as well as high mortality $(2,3)$. Therefore, early local hemostasis treatment and lower portal pressure are very important for patients. In the past, the most common method for the treatment of this disease in clinical practice was to use the three-chamber two-capsule tube to stop bleeding, but the possibility to bleed again, and the high incidence of adverse reactions and complications have limited its use in clinical practice (4). At present, the treatment of liver cirrhosis with gastrointestinal hemorrhage mainly adopts emergency endoscopic therapies and drug treatments. Due to the severity and rapid development of the disease, finding suitable and effective treatment methods is very important for patients (5).

According to the study of D'Amico et al (6), which compared the efficacy and safety between the emergency endoscopic therapy and the drug treatment, the drug treatment has similar efficacy as the emergency endoscopic therapy with fewer side-effects. Octreotide acetate, an octapeptide derivative of synthetic natural somatostatin, is widely used in clinical practice because of its certain control of the blood flow of portal vein and liver, its low incidence of adverse reactions, and because it is usually combined with other drugs due to its short onset time (7). Thrombin, a somatostatin analogue that directly participates in the blood coagulation and promotes the conversion of soluble fibrinogen in the plasma into insoluble fibrin for quick hemostasis, can promote the production of epithelial cells and the healing of body wound, working as a quick-acting local hemostatic $(8,9)$. So far, only a few clinical studies have been reported on the combination of octreotide acetate and thrombin in the treatment of patients with liver cirrhosis 
and gastrointestinal hemorrhage $(10,11)$. Therefore, this study investigated the clinical efficacy of octreotide acetate combined with thrombin.

\section{Patients and methods}

Patient data. A retrospective analysis of 157 patients with liver cirrhosis complicated with gastrointestinal hemorrhage, admitted to the Weifang People's Hospital (Weifang, China), from March 2012 to September 2014, was performed. Seventy-four patients treated with octreotide acetate were set as the octreotide group, aged from 38 to 71 years, with a mean age of $57.37 \pm 3.83$ years, and an average bleeding volume of $643.14 \pm 40.71 \mathrm{ml}$; while 83 patients treated with octreotide acetate combined with thrombin were set as the combination group, aged from 35 to 73 years, with a mean age of $56.18 \pm 4.04$ years, and an average bleeding volume of $636.32 \pm 41.84 \mathrm{ml}$. Inclusion criteria: patients diagnosed with liver cirrhosis with upper gastrointestinal hemorrhage; patients with a complete medical record; patients receiving no relevant treatment in other hospitals. Exclusion criteria: patients with allergic reactions and contraindications for the drugs used in this study; patients who were transferred or died during hospitalization; patients during pregnancy or lactation; patients with gastrointestinal bleeding caused by other diseases; patients with blood diseases or tumors; patients with a communication disorder or cognitive disorder. The study was approved by the Ethics Committee of Weifang People's Hospital. Patients who participated in this research had complete clinical data and cooperated with the medical staff to complete the relevant medical treatment. Signed informed consents were obtained from the patients and/or their guardians.

Methods. Patients were given blood supplement immediately after admission and were asked to follow routine fasting. Then, conventional symptomatic supportive treatments, such as, treatment for acid suppression, liver protection, anti-shock, and maintenance of water and electrolyte balance, were performed to maintain normal body consumption. Patients in the octreotide group were given $0.1 \mathrm{mg}$ octreotide acetate by injection (Chengdu Shengnuo Biopharm Co., Ltd., Chengdu, China; medical product permitted by the China Food and Drug Administration: H20153159), combined with $20 \mathrm{ml}$ of $0.9 \%$ sodium chloride, continuously pumped intravenously at the speed of $0.025-0.05 \mathrm{mg} / \mathrm{h}$ (the injection was continuously pumped until 48-72 $\mathrm{h}$ after the hemostasis); in the combination group, patients were injected with a mixture of $0.1 \mathrm{mg}$ octreotide acetate and 2,000 units of thrombin (Penglai Nuokang Pharmaceutical Co., Ltd., Penglai, China; medical product permitted by the China Food and Drug Administration: $\mathrm{H} 20051840$ ) and $20 \mathrm{ml}$ saline through gastric tube bolus or oral administration once every 4-6 h. The treatment for both groups continued for 3 days.

Regular basic nursing was performed and the fasting time and bedtime of patients were carefully guided to prevent hemorrhoids. Vital signs, such as, the patient's blood pressure, pulse, and breathing were closely observed and recorded. Conditions, such as, nausea, color-change of vomit from brown to bright red, and increased incidence of black and thin stool, it was required to be reported to the nurse immediately, in order to get adjusted treatment and nursing measures. Patients and their family members were informed in detail about the drug name, drug function, dosage, time and method of administration, and effective communication with the patient was required to reduce patients' anxiety and depression and to improve patients' satisfaction toward nursing. All patients were directed to avoid irritating food and to attend follow-up regularly.

\section{Observation indicators and standards}

Observation indicators. Factors, including the average hemostasis time (the time from the start of medication to successful hemostasis), the hospitalization time, the amount of blood transfusion during hospitalization, the efficacy of hemostasis at $24 \mathrm{~h}$ after treatment, the visual analog scale (VAS) score before treatment, and at 24 and $72 \mathrm{~h}$ after treatment, were compared between the octreotide and the combination group.

Evaluation of the treatment efficacy (12), and the VAS scoring standard (13). Significant efficacy: no hematemesis, black stools, or abnormal blood routine examination results within $24 \mathrm{~h}$ after treatment was considered as successful hemostasis; certain efficacy: relieved hematemesis, black stools, and not-obviously-abnormal blood routine examination results within $24 \mathrm{~h}$ after treatment was considered as effective hemostasis; no efficacy: aggravated or not-relieved hematemesis, black stools, and abnormal blood routine examination results within $24 \mathrm{~h}$ after treatment was considered as ineffective hemostasis. Overall effective rate $=$ (number of patients with significant efficacy + number of patients with certain efficacy)/total patient number of the group $x 100 \%$. VAS score: the score ranges from 0 to 10 points, and the higher the score, the higher the patient's pain index is.

Statistical methods. Statistical analysis was carried out using SPSS 17.1 software (Shanghai Yuchuang Network Technology Co., Ltd., Shanghai, China). Count data were expressed as a percentage [n (\%)], and their difference between the two groups was measured by Chi-square test. Measurement data were expressed as the mean \pm standard deviation and their difference between the two groups was compared by $\mathrm{t}$-test. Analysis of variance of repeated measures, with Least Significant Difference test, was used to compare the differences between different time-points. $\mathrm{P}<0.05$ was considered to indicate a statistically significant difference.

\section{Results}

Comparison of clinical data of patients. Considering the accuracy and credibility of the experimental results, factors such as, sex, age, weight, anemia, hematemesis, alcohol abuse, and bleeding location, were compared between the two groups. The difference between the two groups was not found to be statistically significant $(\mathrm{P}>0.05)$, indicating that the two groups are comparable to each other. Table I shows the basic information of the patients.

Comparison of mean hemostasis time and hospitalization time between the octreotide and the combination group. The hemostasis time of patients in the octreotide group was 
Table I. Basic information of patients in the octreotide and the combination group.

\begin{tabular}{|c|c|c|c|c|}
\hline Characteristics & Octreotide group $(\mathrm{n}=74)$ & Combination group $(\mathrm{n}=83)$ & Chi-square test & P-value \\
\hline Sex & & & 0.083 & 0.773 \\
\hline Male & $48(64.86)$ & $52(62.65)$ & & \\
\hline Female & $26(35.14)$ & $31(37.35)$ & & \\
\hline Age (years) & & & 2.412 & 0.120 \\
\hline$\leq 45$ & $33(44.59)$ & $27(32.53)$ & & \\
\hline$>45$ & $41(55.41)$ & $56(67.47)$ & & \\
\hline Weight (kg) & & & 0.004 & 0.947 \\
\hline$\leq 60$ & $29(39.19)$ & $39(46.99)$ & & \\
\hline$>60$ & $45(60.81)$ & $44(53.01)$ & & \\
\hline Anemia & & & 2.575 & 0.109 \\
\hline Yes & $56(75.68)$ & $53(63.86)$ & & \\
\hline No & $18(24.32)$ & $30(36.14)$ & & \\
\hline Hematemesis & & & 0.716 & 0.398 \\
\hline Yes & $27(36.49)$ & $25(30.12)$ & & \\
\hline No & $47(63.51)$ & $58(69.88)$ & & \\
\hline Alcohol abuse & & & 0.801 & 0.371 \\
\hline Yes & $31(41.89)$ & $29(34.94)$ & & \\
\hline No & $43(58.11)$ & $54(65.06)$ & & \\
\hline Bleeding location & & & 0.117 & 0.733 \\
\hline Esophageal variceal & $35(47.30)$ & $37(44.58)$ & & \\
\hline Gastric fundus varices & $39(52.70)$ & $46(55.42)$ & & \\
\hline
\end{tabular}

Table II. Comparison of mean hemostasis time and hospitalization time between the octreotide and the combination group.

\begin{tabular}{lccrr}
\hline Index & Octreotide group $(\mathrm{n}=74)$ & Combination group $(\mathrm{n}=83)$ & t value & P-value \\
\hline Mean hemostasis time (h) & $29.54 \pm 3.28$ & $21.18 \pm 2.76$ & 17.340 & $<0.001$ \\
Hospitalization time (days) & $11.02 \pm 3.13$ & $7.27 \pm 2.67$ & 8.100 & $<0.001$ \\
\hline
\end{tabular}

significantly higher than that in the combination group, and the difference was statistically significant $(\mathrm{t}=17.340, \mathrm{P}<0.001)$. The hospitalization time of the octreotide group was significantly higher than that of the combination group, and the difference was statistically significant $(\mathrm{t}=8.100, \mathrm{P}<0.001)$ (Table II).

Comparison of blood transfusion during hospitalization between the octreotide and the combination group. The blood transfusion volume of the octreotide group $(425.68 \pm 68.35 \mathrm{ml})$ was significantly higher than that of the combination group $(251.41 \pm 51.23 \mathrm{ml})$, and the difference was statistically significant $(\mathrm{t}=18.200, \mathrm{P}<0.001)$ (Fig. 1).

Comparison of hemostatic efficacy between the octreotide and the combination group after treatment. The overall effective rate of the combination group was $97.59 \%$ (58 patients with significant efficacy, 23 patients with certain efficacy, 2 patients with no efficacy); and the overall effective rate of the octreotide group was $89.19 \%$ (47 patients with significant efficacy, 19 patients with certain efficacy, 8 patients

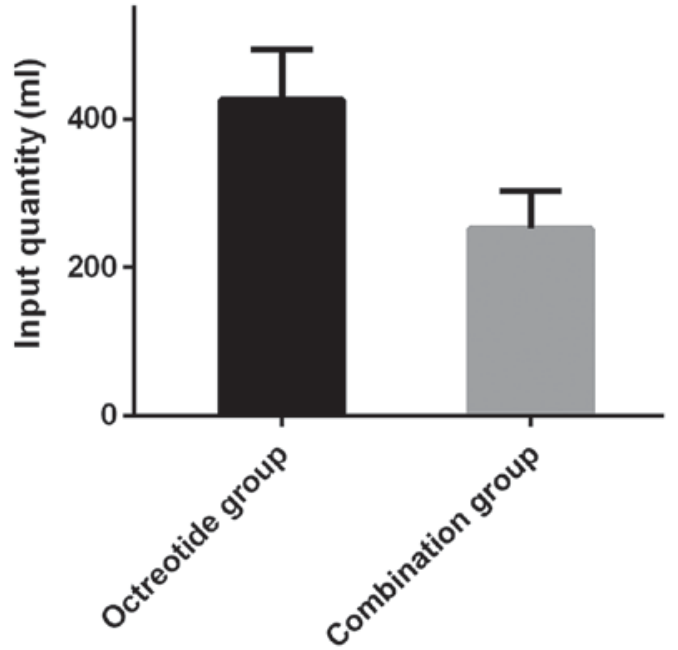

Figure 1. Comparison of the blood transfusion volume during hospitalization between the octreotide and the combination group. The transfusion volume of the octreotide group was $425.68 \pm 68.35 \mathrm{ml}$, which was significantly higher than that of the combination group $(251.41 \pm 51.23 \mathrm{ml})$, and the difference was statistically significant $(\mathrm{t}=18.200, \mathrm{P}<0.001)$. 
Table III. Comparison of the overall effective rate between the octreotide and the combination group after treatment.

\begin{tabular}{lcccc}
\hline Groups & Significant efficacy & Certain efficacy & No efficacy & Overall effective rate \\
\hline Octreotide group $(\mathrm{n}=74)$ & $47(63.51)$ & $19(25.68)$ & $8(10.81)$ & $66(89.19)$ \\
Combination group $(\mathrm{n}=83)$ & $58(69.88)$ & $23(27.71)$ & $2(2.41)$ & $81(97.59)$ \\
Chi-square test & - & - & - & 4.630 \\
P-value & - & - & - & 0.031 \\
\hline
\end{tabular}

Table IV. Comparison of VAS scores between the octreotide and the combination group before and after treatment.

\begin{tabular}{lcrr}
\hline Groups & Octreotide group $(\mathrm{n}=74)$ & Combination group $(\mathrm{n}=83)$ & t value \\
\hline Before treatment & $6.54 \pm 1.76$ & $6.47 \pm 1.87$ & 0.241 \\
24 h after treatment & $5.15 \pm 1.24^{\mathrm{a}}$ & $4.82 \pm 1.33^{\mathrm{a}}$ & 0.810 \\
72 h after treatment & $2.91 \pm 0.84^{\mathrm{a}, \mathrm{b}}$ & $2.14 \pm 0.92^{\mathrm{a}, \mathrm{b}}$ & 0.039 \\
F value & 139.400 & 194.600 & 2.087 \\
P-value & $<0.001$ & $<0.001$ & $<0.001$ \\
\hline
\end{tabular}

${ }^{\mathrm{a}} \mathrm{P}<0.05$, compared to the VAS score before treatment; ${ }^{\mathrm{b}} \mathrm{P}<0.05$, compared to the VAS score at $24 \mathrm{~h}$ after treatment. VAS, visual analog scale.

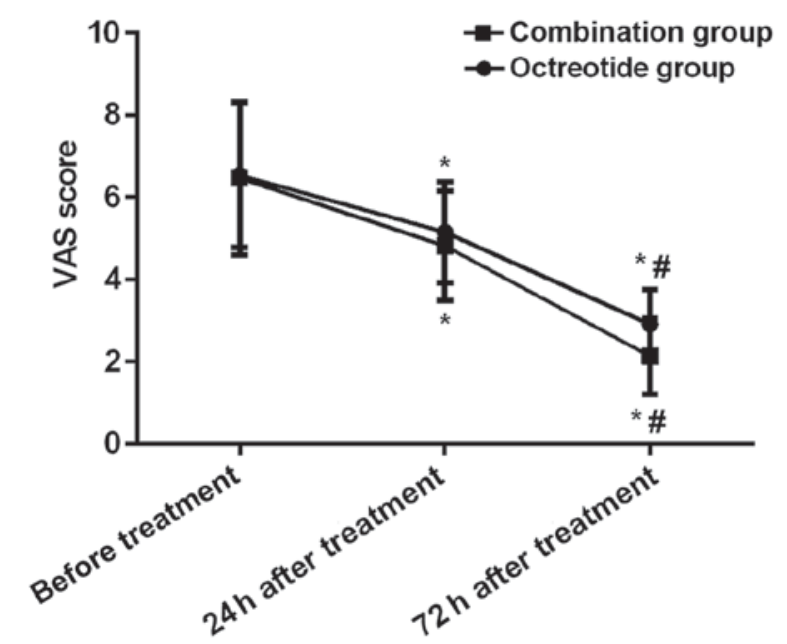

Figure 2. Comparison of VAS scores before and after treatment between the octreotide and the combination group. The VAS scores of both the octreotide and the combination group at 24 and $72 \mathrm{~h}$ after treatment were significantly lower than those before treatment, and the VAS scores at $72 \mathrm{~h}$ after treatmen were significantly lower than that at $24 \mathrm{~h}$ after treatment, and the differences were statistically significant $(\mathrm{P}<0.05)$. ${ }^{*} \mathrm{P}<0.05$, compared to the VAS score before treatment; ${ }^{\#} \mathrm{P}<0.05$, compared to the VAS score at $24 \mathrm{~h}$ after treatment. VAS, visual analog scale.

with no efficacy. The difference in the overall effective rate between the two groups was statistically significant $(\mathrm{P}<0.05)$ (Table III).

Comparison of VAS scores between the octreotide and the combination group before and after treatment. The VAS scores of the combination group at 24 and $72 \mathrm{~h}$ after treatment were lower than those of the octreotide group, and the differences were statistically significant $(\mathrm{P}<0.05)$; the VAS scores of both the octreotide and the combination group at 24 and $72 \mathrm{~h}$ after treatment were significantly lower than those before treatment, and the VAS scores at $72 \mathrm{~h}$ after treatment were significantly lower than that at $24 \mathrm{~h}$ after treatment. The differences were statistically significant $(\mathrm{P}<0.05)$ (Table IV and Fig. 2).

\section{Discussion}

Liver cirrhosis is a diffuse liver damage caused by repeated incidence of liver disease due to one or more etiologies, leading to dysfunction of normal liver lobules and vascular structures, and causing liver fibrosis (14). Patients with liver cirrhosis, which is a common and serious disease in the clinic, have a very high risk of liver cancer, with liver cancer incidence of 2-5\%/ year $(15,16)$. As the society is becoming more modernized, the cause of liver cirrhosis has increased, leading to an increasing trend in the number of patients with liver cirrhosis. As a serious complication of liver cirrhosis, portal hypertension with symptoms, such as, blocked blood flow or increased blood flow, and increased hydrostatic pressure in the portal vein, may cause esophageal and gastric varices bleeding, with an incidence of $23.13 \%$ (17-19). According to the statistics by Lyles et al (20), liver cirrhosis with gastrointestinal hemorrhage has a mortality rate of $\sim 8.4 \%$, which seriously jeopardizes the life of patients.

This study retrospectively analyzed 157 patients with liver cirrhosis complicated with gastrointestinal hemorrhage that were admitted to Weifang People's Hospital, from March 2012 to September 2014. Seventy-four patients were treated with octreotide acetate and 83 patients were treated with octreotide acetate and thrombin, and then comprehensively compared factors between the two groups, such as, the treatment efficacy, mean hemostasis time, hospitalization time, blood transfusion volume during hospitalization, and VAS score, were investigated. The results revealed that the mean hemostasis time and hospitalization time of the combination group were 
significantly shorter than the that of the octreotide group. Octreotide and thrombin can increase the contractile force of the low esophageal sphincter, can assist to reduce the reflux of gastric contents, protect the esophageal mucosa, promote platelet aggregation, and increase the coagulation rate (21).

DeLaney and Greene (22), in their study on the efficacy of octreotide and thrombin treatment in patients with upper gastrointestinal bleeding, have pointed out that the average hemostasis time and symptom-relieving time of patients treated with octreotide acetate and thrombin are significantly reduced, which further corroborates our research. The present study found that the patients in the octreotide group have significantly more blood transfusion during hospitalization than those in the combination group; the overall effective rate of combination group (97.59\%), was found to be significantly greater than that of the octreotide group $(89.19 \%)$. The above differences were all statistically significant. Since octreotide acetate can reduce the production and release of vasodilators (such as, glucagon, vasoactive intestinal peptide), it can reduce the total blood flow to the liver, reduce the blood flow of the portal vein, and keep the human hemodynamics relatively stable (23).

The efficacy of octreotide was discovered by Zhou et al (24) who reported on the hemostasis efficacy of lansoprazole combined with different dosages of octreotide in the treatment of liver cirrhosis with upper gastrointestinal bleeding. However, due to the pharmacological properties of octreotide acetate, such as, the short onset time and some adverse reactions, octreotide was not recommended to be used alone. Thrombin, a somatostatin analogue that can quickly convert the blood acting on the surface of the lesion into a stable blood clot after local application and have a relatively small incidence of adverse reactions, is suitable for the hemostasis of small blood vessels, capillaries and parenchymal viscera in which it is difficult to achieve hemostasis by ligation (25).

Friedlander et al (26) have reported that the combination of octreotide acetate and somatostatin significantly improves the recovery of white blood cells, blood glucose and blood calcium in patients with pancreatitis, compared to the single use of octreotide acetate or somatostatin, and achieves a reduction in the incidence of complications, which is supportive of the results of the present study. No literature exists on lower VAS scores of patients treated with octreotide acetate combined with somatostatin compared to those of patients treated with octreotide acetate alone, which is therefore of research value to be further studied. The severe liver damage and obvious systemic symptoms, such as, jaundice, fatigue and poor coagulation function may worsen the depression of patients with liver cirrhosis, so, medical staff should promptly give a psychological guide to patients and patiently respond to questions from patients and/or their families (27). Since upper gastrointestinal bleeding may cause shock or even death of the patient, the medical staff need to pay attention to the patient's vital signs in a timely manner, strengthen the basic nursing, implement predictive care, and prepare a series of nursing interventions, such as, emergency care for possible bleeding (28). Good communication between nurses and patients and nursing interventions, if combined with drug treatment, will benefit patients' compliance and rehabilitation, worthy of clinical promotion and application.
In this experiment, the sample size was relatively small due to the small number of patients with liver cirrhosis complicated with upper gastrointestinal hemorrhage in the above hospital, and therefore, the results might have some contingency. Thus, the authors will continue the follow-up for a longer period of time.

In summary, octreotide acetate and thrombin in the treatment of liver cirrhosis complicated with gastrointestinal bleeding can relieve the clinical symptoms of patients and achieve good efficacy and high safety, worthy of promotion in clinical practice.

\section{Acknowledgements}

Not applicable.

\section{Funding}

No funding was received.

\section{Availability of data and materials}

The datasets used and/or analyzed during the present study are available from the corresponding author on reasonable request.

\section{Authors' contributions}

XW was responsible for the writing of the manuscript. XW and JZhang recorded and analyzed the observation indicators. YL and JZhao acquired and interpreted the patients' general data. XW assisted with the evaluation of the treatment efficacy and the VAS scoring. All authors read and approved the final manuscript.

\section{Ethics approval and consent to participate}

The study was approved by the Ethics Committee of Weifang People's Hospital (Weifang, China). Patients who participated in this research had complete clinical data and cooperated with the medical staff to complete the relevant medical treatment. Signed informed consents were obtained from the patients and/or their guardians.

\section{Patient consent for publication}

Not applicable.

\section{Competing interests}

The authors declare that they have no competing interests.

\section{References}

1. Fukui H, Saito H, Ueno Y, Uto H, Obara K, Sakaida I, Shibuya A, Seike M, Nagoshi S, Segawa M, et al: Evidence-based clinical practice guidelines for liver cirrhosis 2015. J Gastroenterol 51: 629-650, 2016.

2. Cancela E, Ministro P, Peixoto P, Sadio A, Castanheira A, Silva A and Caldas A: Concomitant life threatening lesions in a cirrhotic patient: The value of endoscopic treatment. Rev Esp Enferm Dig 102: 617-618, 2010. 
3. Abid S, Jafri W, Hamid S, Salih M, Azam Z, Mumtaz K, Shah HA and Abbas Z: Terlipressin vs. octreotide in bleeding esophageal varices as an adjuvant therapy with endoscopic band ligation: A randomized double-blind placebo-controlled trial. Am J Gastroenterol 104: 617-623, 2009.

4. Escorsell À, Pavel O, Cárdenas A, Morillas R, Llop E, Villanueva C, Garcia-Pagán JC and Bosch J; Variceal Bleeding Study Group: Esophageal balloon tamponade versus esophageal stent in controlling acute refractory variceal bleeding: A multicenter randomized, controlled trial. Hepatology 63: 1957-1967, 2016.

5. Drastich P, Lata J, Petrtyl J, Bruha R, Prochazka V, Vanasek T, Zdenek P, Skibova J, Hucl T and Spicak J: Endoscopic variceal band ligation compared with propranolol for prophylaxis of first variceal bleeding. Ann Hepatol 10: 142-149, 2011.

6. D'Amico G, Pietrosi G, Tarantino I and Pagliaro L: Emergency sclerotherapy versus vasoactive drugs for variceal bleeding in cirrhosis: A Cochrane meta-analysis. Gastroenterology 124 : 1277-1291, 2003

7. Garbuzenko DV: Current approaches to the management of patients with liver cirrhosis who have acute esophageal variceal bleeding. Curr Med Res Opin 32: 467-475, 2016.

8. Crean S, Michels SL, Moschella K and Reynolds MW: Bovine thrombin safety reporting: An example of study design and publication bias. J Surg Res 158: 77-86, 2010.

9. Ballard JL, Weaver FA, Singla NK, Chapman WC and Alexander WA: Safety and immunogenicity observations pooled from eight clinical trials of recombinant human thrombin. J Am Coll Surg 210: 199-204, 2010.

10. Ludwig D, Schädel S, Brüning A, Schiefer B and Stange EF: 48-hour hemodynamic effects of octreotide on postprandial splanchnic hyperemia in patients with liver cirrhosis and portal hypertension: Double-blind, placebo-controlled study. Dig Dis Sci 45: 1019-1027, 2000.

11. Chaireti R, Rajani R, Bergquist A, Melin T, Friis-Liby IL, Kapraali M, Kechagias S, Lindahl TL and Almer S: Increased thrombin generation in splanchnic vein thrombosis is related to the presence of liver cirrhosis and not to the thrombotic event. Thromb Res 134: 455-461, 2014.

12. Kanai M, Hamada A, Endo Y, Takeda Y, Yamakawa M, Nishikawa $\mathrm{H}$ and Torii A: Efficacy of argon plasma coagulation in nonvariceal upper gastrointestinal bleeding. Endoscopy 36: 1085-1088, 2004.

13. Boonstra AM, Schiphorst Preuper HR, Balk GA and Stewart RE: Cut-off points for mild, moderate, and severe pain on the visual analogue scale for pain in patients with chronic musculoskeletal pain. Pain 155: 2545-2550, 2014.

14. Ge PS and Runyon BA: Treatment of patients with cirrhosis. N Engl J Med 375: 767-777, 2016.

15. Li L, Liu W, Chen YH, Fan CL, Dong PL, Wei FL, Li B, Chen DX and Ding HG: Antiviral drug resistance increases hepatocellular carcinoma: A prospective decompensated cirrhosis cohort study. World J Gastroenterol 19: 8373-8381, 2013.

16. Guo $\mathrm{LH}$ and $\mathrm{Xu} \mathrm{HX}$ : Contrast-enhanced ultrasound in the diagnosis of hepatocellular carcinoma and intrahepatic cholangiocarcinoma: Controversy over the ASSLD guideline. BioMed Res Int 2015: 349172, 2015.
17. Schuppan D and Afdhal NH: Liver cirrhosis. Lancet 371: 838-851, 2008.

18. Zou D, Qi X, Zhu C, Ning Z, Hou F, Zhao J, Peng Y, Li J, Deng $\mathrm{H}$ and Guo X: Albumin-bilirubin score for predicting the in-hospital mortality of acute upper gastrointestinal bleeding in liver cirrhosis: A retrospective study. Turk J Gastroenterol 27: 180-186, 2016.

19. Romcea AA, Tanţău M, Seicean A and Pascu O: The etiology of upper gastrointestinal bleeding in cirrhotic patients. Clujul Med 86: 21-23, 2013.

20. Lyles T, Elliott A and Rockey DC: A risk scoring system to predict in-hospital mortality in patients with cirrhosis presenting with upper gastrointestinal bleeding. J Clin Gastroenterol 48: 712-720, 2014.

21. Tripathi D, Stanley AJ, Hayes PC, Patch D, Millson C, Mehrzad H, Austin A, Ferguson JW, Olliff SP, Hudson M, et al; Clinical Services and Standards Committee of the British Society of Gastroenterology: U.K. guidelines on the management of variceal haemorrhage in cirrhotic patients. Gut 64: 1680-1704, 2015.

22. DeLaney M and Greene CJ: Emergency department evaluation and management of patients with upper gastrointestinal bleeding. Emerg Med Pract 17: 1-19, 2015.

23. Mocarzel LO, Bicca J, Jarske L, Oliveira T,Lanzieri P, Gismondi R and Ribeiro ML: Cirrhotic cardiomyopathy: Another case of a successful approach to treatment of hepatorenal syndrome. Case Rep Gastroenterol 10: 531-537, 2016.

24. Zhou DX, Zhou HB, Wang Q, Zou SS, Wang H and Hu HP: The effectiveness of the treatment of octreotide on chylous ascites after liver cirrhosis. Dig Dis Sci 54: 1783-1788, 2009.

25. Fu X, Tian P, Xu GJ, Sun XL and Ma XL: Thrombin-based hemostatic agent in primary total knee arthroplasty. J Knee Surg 30: 121-127, 2017.

26. Friedlander TW, Weinberg VK, Small EJ, Sharib J, Harzstark AL, Lin AM, Fong L and Ryan CJ: Effect of the somatostatin analog octreotide acetate on circulating insulin-like growth factor-1 and related peptides in patients with non-metastatic castration-resistant prostate cancer: Results of a phase II study. Urol Oncol 30: 408-414, 2012.

27. Kim SH, Oh EG and Lee WH: Symptom experience, psychological distress, and quality of life in Korean patients with liver cirrhosis: A cross-sectional survey. Int J Nurs Stud 43: 1047-1056, 2006.

28. Yang F, Xiang ML and Liu YM: Thrombin in combination with intensive nursing in treating upper gastrointestinal bleeding in children. J Biol Regul Homeost Agents 30: 491-495, 2016.

This work is licensed under a Creative Commons Attribution-NonCommercial-NoDerivatives 4.0 International (CC BY-NC-ND 4.0) License. 